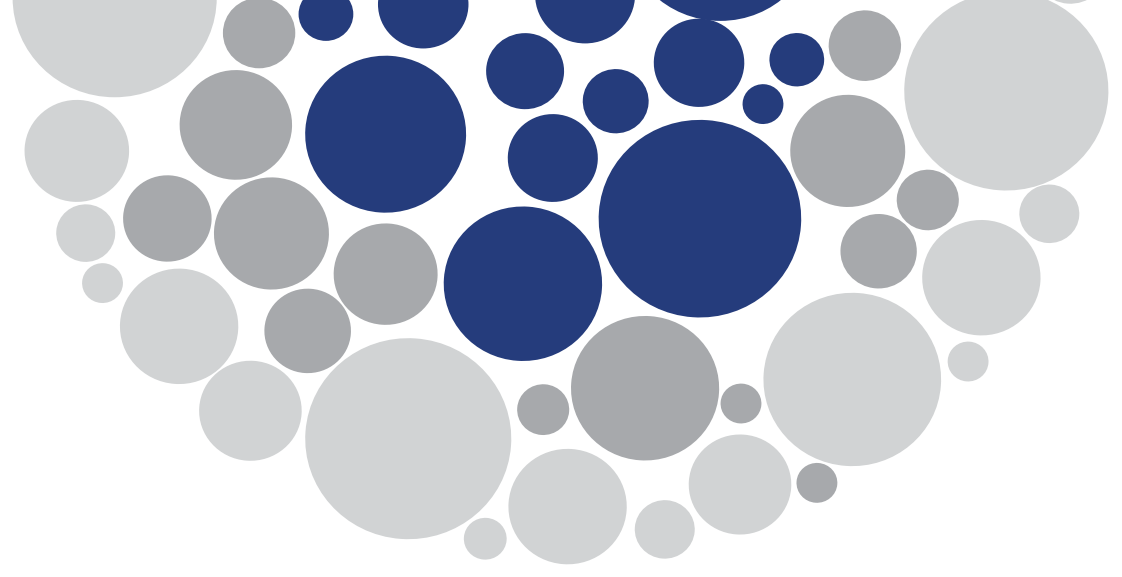

\title{
Geografia Histórica como método
}

\begin{abstract}
Glauco Bruce Rodrigues ${ }^{a}$
a Departamento de Geografia, Programa de Pós-Graduação em Geografia da Universidade Federal Fluminense - Campos dos Goytacazes (UFF/Campos). Núcleo de Estudos sobre o Território e Conflitos Sociais. E-mail: glauco_bruce@id.uff.br.
\end{abstract}

No livro Geography and History: bridging the divide, o geógrafo Alan Baker (2003) elabora sete princípios gerais sobre a Geografia Histórica, dos quais dois são mais relevantes para nossa discussão. O primeiro afirma que a Geografia Histórica questiona o passado, assim como a História ${ }^{1}$. O segundo afirma que a Geografia Histórica se dedica, fundamentalmente, à mudança geográfica através do tempo². Tais princípios, elaborados no final do livro, buscam realizar uma síntese teórica que permita ao autor circunscrever a singularidade da Geografia Histórica e, dessa forma, defendê-la como um campo de pesquisa específico no interior da disciplina. Em outras palavras, os sete princípios funcionam como balizadores teóricos que, devidamente articulados, justificam e legitimam pensar a Geografia Histórica como um campo específico e singular da Geografia, com autonomia própria. De forma sintética, os dois princípios que destacamos são exatamente aqueles que seriam, de maneira efetiva, os traços definidores e, portanto, distintos e próprios deste campo, caracterizado pelo estudo de geografias do passado ou por processos de transformações do espaço, do lugar, da região, da paisagem ou do território ao longo do tempo. De qualquer forma, o traço que caracteriza a diferenciação e singulariza a Geografia Histórica é o estudo do passado.

Durante o III Encontro Nacional de História do Pensamento Geográfico e I Encontro Nacional de Geografia Histórica, realizado na Universidade Federal do Rio de Janeiro, em novembro de 2012, o professor Pedro Vasconcelos apresentou um trabalho intitulado

\footnotetext{
1 "The first of my seven principles is that historical geography, like history, asks questions about the past" (BAKER, 2003, p. 209, grifos do autor).

2 "My fourth principle is that historical geography is essentially concerned with geographical change through time" (BAKER, 2003, p. 215, grifos do autor).
} 
Geografia Histórica: campo disciplinar e questões de pesquisa $a^{3}$ Partindo de um abrangente levantamento bibliográfico, o autor coloca como ponto de partida de sua reflexão a própria definição do que seria a Geografia Histórica, chamando a atenção para a diversidade de definições e perspectivas encontradas ao longo do tempo, em que a Geografia Histórica foi definida, por exemplo, como "a descrição de uma área no passado" (HETTNER, 1898 apud VASCONCELOS, 2012, p. 1), “o estudo geográfico de qualquer período do passado" (MITCHELL, 1954 apud VASCONCELOS, 2012, p. 1), "o estudo das mudanças geográficas através do tempo" (DARBY, 1954 apud VASCONCELOS, 2012, p. 1), o “estudos das geografias do passado" (BUTLIN, 1993 apud VASCONCELOS, 2012, p. 1), "toda a geografia conjugada a toda história, nas preocupações e os métodos mais variados dessas disciplinas" (PITTE, 2005 apud VASCONCELOS, 2012, p. 1) e, finalmente, "como o estudo geográfico do passado, destacando o interesse principal é com as mudanças geográficas através do tempo" (BAKER, 2003 apud VASCONCELOS, 2012, p. 2). Podemos observar que as definições, em sua maior parte, são tentativas de estabelecer a Geografia Histórica como um campo da disciplina dedicado, principalmente, ao estudo de geografias do passado e mudanças de caráter geográfico através do tempo.

Em um artigo de revisão, Patrício Carneiro (2016) nos apresenta um amplo panorama da Geografia Histórica entre os séculos XIX e início do XXI, destacando o esforço realizado para a constituição de um campo específico dentro da Geografia. Entre as décadas de 1940 e 1960, segundo o autor, criaram-se, efetivamente, as bases para a instituição da Geografia Histórica como um campo a partir dos esforços de geógrafos como Carl Sauer, Henry Darby, Andrew Clark e Donald Meinig: "Esses pesquisadores lutaram pela incorporação do tempo nas análises geográficas e mostraram que pensar historicamente é parte essencial do ato de fazer geografia humana" (CARNEIRO, 2016, p. 61). A forma como incorporaram a história e o tempo pode ser resumida como o estudo de geografias do passado e das transformações geográficas ao longo do tempo.

No texto que funda a moderna Geografia Histórica, publicado no Annals of the Association of American Geographers, em 1941, Carl Sauer propõe pensar na Geografia Humana como Geografia Histórica-Cultural (SAUER, 2004, p. 8). Tal formulação pode nos dar a ideia da dimensão da ambição dos geógrafos que se dedicaram à afirmação da Geografia Histórica como campo.

Em trabalho recente, Carlo Eugênio Nogueira (2019) também chama a atenção para o predomínio (e não exclusividade) da concepção de que a Geografia Histórica constitui um campo caracterizado pelo estudo das geografias do passado, apontando, a partir desse diagnóstico, para algumas transformações pelas quais esse campo estaria passando:

Desse modo, há um deslocamento do objeto de estudo da Geografia Histórica, com a atenuação do desejo cego pela reconstrução da materialidade das geografias passadas e o reconhecimento da importância das representações nas ações de apropriação e transformação do espaço. Isto é, valoriza-se a análise do lugar dos discursos geográficos na elaboração de projetos que embasam políticas que visam ordenar a construção dos territórios, em um registro que se aproxima de um exame geográfico da experiência histórica (Zusman, 2000) (NOGUEIRA, 2019, p. 2).

\footnotetext{
${ }^{3} \mathrm{O}$ trabalho, infelizmente, não foi publicado, porém o texto apresentado foi repassado pelo próprio autor.
} 
Os cinco autores que nos auxiliam a colocar a questão não deixam dúvidas: a Geografia Histórica, em toda sua diversidade e complexidade, é pensada, de forma majoritária, como um campo específico e autônomo da Geografia.

A primeira questão a se colocar refere-se, exatamente, ao processo de institucionalização da Geografia Histórica como um campo particular de pesquisa na Geografia. O que constituiu um campo de pesquisa em uma disciplina, no caso em questão, a Geografia? Um campo é constituído por um conjunto relativamente restrito e delimitado de questões, constituídas por fenômenos e processos que possuem certa identidade e significativa articulação, que nos permitem a construção limitada de um certo número de objetos. Em outras palavras, um campo é caracterizado por um conjunto de processos e fenômenos relativamente semelhantes e que se distinguem de outros campos pela diferença dos conteúdos. Assim, Geografia Urbana, Geografia da População, Geografia da População, Geografia dos Ativismos Sociais são campos específicos de pesquisa em Geografia, porque são constituídos por fenômenos e processos com forte identidade entre si, com um conjunto específico de questões que os diferenciam uns dos outros. Evidentemente, os campos dialogam, e seus processos, fenômenos, questões e objetos perpassam uns pelos outros, no entanto é possível circunscrever a singularidade de cada um, seu cerne, seu conteúdo fundamental.

Um excelente exemplo de definição de um campo pode ser encontrado no texto de Allen Scott e Michael Storper (SCOTT; STORPER, 2018), no qual os autores se propõem a explicitar um conceito de urbano para que possa servir como elemento definidor de um campo específico de pesquisa, no caso em tela, os estudos urbanos. Eles colocam a questão da seguinte forma:

Dito isto, nosso objetivo geral neste artigo não é envolver-se em uma crítica detalhada da literatura e, certamente, não negar que as cidades exibem uma variação empírica considerável ao longo do tempo e do espaço ou que as cidades podem ser estudadas de forma aproveitável como casos únicos. Em vez disso, estamos preocupados em tentar construir um conceito geral do urbano e do processo de urbanização que acreditamos poder ajudar a trazer um vocabulário comum aos debates que proliferam dentro deste campo. Qualquer conceito desse tipo também contribuirá para a pesquisa sobre as cidades, ao nos fornecer indicadores que facilitam a tarefa crucial de demarcar a lógica interna da urbanização diferenciando-a de outros processos sociais. Assim, pensamos que nossa abordagem teórica realmente ajuda a iluminar em vez de distorcer as particularidades de cidades específicas e de grupos de cidades. Pelo menos parte da cacofonia na literatura de estudos urbanos pode, em parte, ser rastreada ao fracasso dos pesquisadores em serem claros sobre essas questões de definição e demarcação (SCOTT; STORPER, 2018, p. 9, grifos nossos).

Os autores colocam a necessidade da explicitação clara e lógica da demarcação e explicitação do campo de pesquisa. Tal campo se constitui a partir da seleção de um certo número de questões, processos e fenômenos que possuem forte identidade e inter-relações estruturais e conjunturais. É essa explicitação que justifica e legitima a seleção de dados empíricos que sustentam a construção de objetos de pesquisa que serão utilizados para a análise das questões centrais. Assim, a demarcação de um campo demanda a formalização lógica dos elementos centrais que o singularizam e o diferenciam de outros. Dessa forma, por maior que seja a diversidade teórica e temática, a comunidade de pesquisadores de determinado campo se reconhece a partir de uma identidade comum, dada pelas questões, processos e fenômenos singulares que demarcam o campo. 
Scott e Storper (2018) buscam explicitar tal demarcação a partir da produção de conceitos que consigam apreender elementos gerais que estejam presentes nos mais diversos tipos de manifestações empíricas distintas da cidade e do urbano. Em outras palavras, os autores se propõem a produzir um conceito geral que permita demarcar um campo e, ao mesmo tempo, reconhecer a singularidade de cada cidade por meio da pesquisa. Para os autores, trata-se de se delimitar, de forma clara, o campo dos estudos urbanos. Mas o que isso significa? Coloca-se a necessidade de se "distinguir as dinâmicas da vida social que são intrinsecamente urbanas daquelas que são mais propriamente vistas como situadas fora da esfera estrita do urbano, mesmo quando são detectadas como uma questão de ocorrência empírica dentro das cidades" (SCOTT; STORPER, 2018, p. 23-24). Assim, constitui um campo de pesquisa específico denominado estudos urbanos, que é um campo específico dentro das Ciências Sociais e que pode assumir aspectos particulares dentro de cada disciplina, como na Geografia Urbana, Sociologia Urbana, Antropologia Urbana etc.

No entanto, a Geografia Histórica não satisfaz tais condições, e esse argumento pode ser desenvolvido a partir de dois pontos.

O primeiro refere-se à falta absoluta de um conjunto específico de processos e fenômenos que permita a construção de um corpo teórico e conceitual comum para se debater um conjunto mais ou menos comum de questões e problemas. Em outras palavras, o universo de questões, processos e fenômenos da Geografia Histórica é ilimitado. Não há, minimamente, um conjunto relativamente comum de questões e objetos construídos capazes de circunscrever um campo.

Por exemplo, no texto fundador da Geografia Histórica moderna, Introdução à Geografia Histórica, Carl Sauer enumera alguns temas desse suposto campo (SAUER, 2004, p.16-22): a) processos físicos que podem afetar o homem; b) homem como agente da Geografia Física; c) sítios de assentamentos humanos; d) modelos de assentamento; e) tipo de habitação; f) clímax cultural; g) receptividade cultural; h) distribuição da energia em uma área cultural; i) estados e sucessão cultural. Sem dúvida, é uma agenda de pesquisa alinhada com seu tempo e com uma perspectiva conservadora de Geografia.

William Norton (1984), em seu livro Historical analysis in geography, destacou cinco temas de interesse para a Geografia Histórica: 1) a exploração, a imigração e as fronteiras; 2) a evolução dos assentamentos rurais e urbanos; 3) a paisagem rural; 4) o transporte e as paisagens industriais e urbanas; 5) a população e as análises sociais.

No texto já citado de Pedro Vasconcelos, o autor comenta o conjunto de temas trabalhados em um livro organizado em 2003 em homenagem a Alan Baker:

No livro em homenagem ao geógrafo histórico Alan Baker, organizado por Black e Butlin (2001), dois textos teóricos são seguidos por textos com comentários às viagens de J. Locke; as representações da Palestina; aos restaurantes de Paris; a história dos teatros na Itália; aos espaços de prostituição nas cidades europeias; aos intelectuais franceses e a questão da Alsácia-Lorena; ao discurso dos camponeses na França rural; a ponte Vitória em Montreal; ao discurso colonial no Quebec; e a identidade nacional canadense (VASCONCELOS, 2012, p. 3).

Diante de tamanha diversidade temática, Pedro Vasconcelos faz o seguinte diagnóstico: "Essa dispersão temática, a meu ver, fragiliza a subdisciplina" (VASCONCELOS, 2012, p. 3, grifos nossos). Aqui, subdisciplina é sinônimo de campo. A fragilidade apontada 
por um dos principais geógrafos que constituíram a Geografia Histórica brasileira deve ser levada muito a sério. A fragilidade está na impossibilidade da constituição de um campo cujas questões centrais sejam compartilhadas pela comunidade que o sustenta. É possível que sejam compartilhadas perspectivas e formulações teóricas em comum, de caráter mais geral, assim como procedimentos metodológicos específicos e utilizados pelos pesquisadores que constituem o suposto campo. Mas isso pode ser extrapolado, de forma mais ampla, para o conjunto da chamada Geografia Humana e Geografia Física. Em outra escala, pode ser extrapolado para o conjunto das Ciências Sociais e das Ciências da Natureza. O fundamental, o alicerce, o cerne não passa por esses elementos, mas sim pelas questões concretas, pelos problemas levantados, em suma, pelo conjunto de questões, processos e fenômenos. A dispersão temática é capaz de causar a impossibilidade do diálogo em função do desinteresse pelo o que está sendo dito pelo outro. Assim, criam-se, de um lado, uma dissociação entre teoria e método e, de outro, a análise concreta do empírico. Os debates conceituais animam, mas as pesquisas concretas levam ao desinteresse. Em síntese, é necessário um conteúdo empírico concreto ao recorte temporal como ocorre na História, cujos campos possuem um conteúdo empírico associado ao tempo: História Antiga, História Medieval, História do Brasil Colonial, História da América Colonial, História da África, História Moderna, História Contemporânea etc.

O segundo ponto que nos leva a defender a impossibilidade de se pensar na Geografia Histórica como um campo é exatamente o elemento de singularização utilizado. De forma geral, qual argumento é utilizado para se definir a Geografia Histórica e marcar sua distinção em relação aos demais campos da Geografia? Em uma primeira aproximação, o traço de diferenciação seria a incorporação explícita da História na produção das pesquisas. Claude Cortez, no livro Geografía Histórica (CORTEZ, 1991, p. 12), coloca a questão da seguinte forma: a Geografia Histórica "podría definir en primera aproximación como a percepción temporal de los problemas espaciales". A "percepção" temporal nas pesquisas seria o indicador da historicidade e, portanto, o demarcador do campo. Assim, a distinção da Geografia Histórica seria a explicitação da dimensão propriamente histórica da pesquisa em Geografia. No entanto, como essa "percepção" temporal expressou, efetivamente, o caráter histórico das pesquisas? Em relação aos pioneiros da Geografia Histórica moderna (1940 a 1960), Patrício Carneiro (2016, p. 53) afirma que:

Guelke (1997, p. 224) analisou essa relação entre a geografia e a história presente nos trabalhos de Darby, Sauer e Clark. Sua conclusão é taxativa: avaliando os princípios teóricos subjacentes nas obras desses autores, pode-se afirmar que os geógrafos históricos citados não compreenderam a história como algo a mais do que o "tempo" ou o "passado". Ou seja, segundo Guelke (1997, p. 224), suas geografias históricas nada mais são do que "a descrição das alterações produzidas pelo homem na transformação de seus ambientes físicos".

O diagnóstico é duro e um pouco injusto. Se é verdade que a descrição e a narrativa eram elementos predominantes, a Geografia Histórica produzida por esses autores não poderia ser reduzida a isso. No entanto, a crítica é correta ao chamar a atenção para a deficiência com que a História foi incorporada. O que podemos apreender dessa análise é que os trabalhos dos principais geógrafos que instituíram a Geografia Histórica não aprofundaram o conteúdo dos conceitos históricos. Quando Guelke afirma que eles não compreenderam a História como algo a mais do que o "tempo" ou o "passado", ele 
quer dizer que os geógrafos se restringiram à superfície do conteúdo dessas categorias e não extraíram delas todas suas consequências teóricas, metodológicas e políticas. Mas voltaremos a essa questão depois.

A História foi reduzida ao tempo no sentido de duração (transformações e permanências) e contagem (com o passar dos anos, dos séculos), mas sem que fossem extraídas as consequências mais profundas desses elementos, que, sem dúvida, constituem a História enquanto disciplina e a História enquanto vida concreta. Seu significado tornou-se banal no sentido de expressar constatações óbvias (a paisagem muda, o tempo age sobre as feições da superfície terrestre, o contexto é importante para compreender tal lugar etc.). Tais constatações pouco contribuem de fato para a análise e funcionam mais como demarcadores cronológicos do que efetivamente históricos. O uso da categoria tempo, ainda que de forma superficial, é utilizado para explicitar a ideia de movimento, dinâmica e transformação. Sem dúvida, existe essa dimensão intrínseca ao tempo histórico, no entanto não constituiu propriamente uma novidade na Geografia, uma vez que essa ideia já estava presente nas obras de Ratzel, La Blache e Reclus, por exemplo.

O mesmo pode ser dito em relação ao passado. Quando o conteúdo dessa temporalidade não é devidamente explorado e aprofundado, ele se torna banal. Assim, não consegue participar de forma ativa da análise e se torna um demarcado cronológico, e não necessariamente histórico. É preciso compreender isto: a demarcação cronológica da pesquisa de uma paisagem ou lugar no passado não necessariamente exprime um conteúdo histórico. O conteúdo histórico só será incorporado se as categorias históricas para pensar na ação social forem explicitadas e aprofundadas. Por enquanto, podemos concluir que o "passado" foi utilizado como demarcador cronológico em oposição ao presente, no entanto sem a devida qualificação efetivamente histórica do seu conteúdo. Essa demarcação, feita com pouca substância teórica, transforma o passado em uma moldura, um quadro de referência com pouca ou nenhuma participação ativa na análise. Seria o equivalente a pensar o espaço como um palco no qual as ações se desenrolam.

Esse seria o diagnóstico geral para o período de 1940 a 1960, caracterizado pelo predomínio dos geógrafos que se dedicaram a instituir o campo da Geografia Histórica, com destaque para Carl Sauer, Henry Darby, Andrew Clark e Donald Meinig.

O que podemos dizer, de forma geral, sobre o estado da Geografia Histórica atual?

Sem dúvida, ocorreram muitos avanços no debate teórico e metodológico, principalmente em língua inglesa e francesa, em relação às categorias de tempo, temporalidade e historicidade, assim como na ampliação dos temas de pesquisa, como já apontou Pedro Vasconcelos, citado anteriormente. Esse avanço pode ser consultado, por exemplo, nas obras de Derek Gregory (1978, 1982), Lawrence Estavile (1991), David Lowenthal (1998), Maurício Abreu (1998, 2000, 2010), Pedro Vasconcelos (1999, 2002, 2009, 2012), Alan Baker (2003), entre outros. Portanto, houve um avanço quanto à crítica elaborada por Guelke, e a Geografia Histórica, certamente, não pode ser caracterizada pelo predomínio da descrição de lugares e paisagens ou da narrativa de fatos e eventos desprovida de análise. No entanto, há um elemento que não foi questionado: o uso do passado como demarcador do campo. Seja como o estudo de geografias do passado, seja como processos do passado que influenciam e constituem o presente, a Geografia Histórica ainda busca utilizar como elemento de distinção o passado.

Agora, vamos examinar criticamente essa formulação. O adjetivo que qualifica o suposto campo é "histórica". Portanto, o geógrafo deve buscar na História elementos 
que permitam, de forma densa e explícita, qualificá-la dessa forma. Tal necessidade conduz, obrigatoriamente, a uma aproximação dialógica com a História: seus conceitos, procedimentos metodológicos e campos temáticos. Aproximação dialógica não significa a conversão do geógrafo em historiador, tampouco o abandono das tradições e do corpo teórico e metodológico da Geografia, mas sim o enriquecimento mútuo, a apropriação de uma série de formulações e procedimentos próprios da História.

É exatamente esse diálogo crítico com a História que nos leva a rechaçar a ideia de definir a Geografia Histórica como um campo caracterizado pelo estudo das geografias do passado.

Em primeiro lugar, a própria História não se define como uma ciência que estuda o passado. O historiador francês Marc Bloch (2009) é enfático: a História é a ciência dos homens no tempo, cuja categoria fundamental é a de duração, que remete diretamente às ideias de temporalidade e historicidade. Portanto, o demarcador do campo disciplinar não é a temporalidade do passado, mas a dimensão temporal da ação social, o que constitui, efetivamente, o tempo histórico, o tempo dos historiadores (BARROS, 2013). O passado em si deixou de ser o elemento que sustenta o corte epistemológico da própria História. A transformação teórica e conceitual que se operou na disciplina a partir da primeira metade do século XX, com destaque para a Escola dos Annales, libertou a História da prisão de reconstruir exatamente o passado tal qual ele era e a colocou diante de problemas e questões a ser examinados a partir da temporalidade e da historicidade, ou seja, da dimensão temporal da ação social. Isso permitiu uma profunda transformação na forma de se produzir História e, ao mesmo tempo, permitiu a disciplina avançar sobre um tempo que estava proibida até então: o presente.

Não seria importante a Geografia Histórica rever seu pressuposto fundamental, aquele que é utilizado como demarcador de um campo específico? Assim, se a História não deve ser circunscrita ao passado nem se define por esse horizonte temporal, por que a Geografia Histórica deveria ficar circunscrita ou ser definida, a priori, pelo estudo do passado? Se considerarmos seriamente o adjetivo "histórico", devemos buscar seu significado mais profundo no seu campo disciplinar originário, que é a História. Isso implica o aprofundamento teórico, conceitual e metodológico das categorias históricas que são utilizadas por aqueles que produzem Geografia Histórica. As categorias de duração, permanência, temporalidade (passado, presente e futuro), longa duração, conjuntura, evento e historicidade ${ }^{4}$, por exemplo, demandam um tratamento muito mais rigoroso do que as constatações de que "a paisagem muda", "o contexto é importante", "a origem histórica dos elementos que estruturam o espaço".

Porém, antes de dar continuidade, abrimos um parêntese fundamental: aqui não queremos dizer que os geógrafos nunca realizaram esse esforço ou que nunca se deram conta dessas questões, o que seria um absurdo. No entanto, podemos constatar duas coisas: 1) não houve uma apreciação mais substancial sobre a questão da Geografia Histórica como campo;2) tais reflexões ficam restritas, majoritariamente, a um conjunto relativamente reduzido de geógrafos e são pouco perceptíveis no conjunto mais amplo da produção, seja em dissertações, teses e artigos. Pronto, fechamos o parêntese.

\footnotetext{
${ }^{4}$ Ver, por exemplo, as obras de Marc Bloch (2009), Fernando Novais (2005), Reinhart Koselleck (2006, 2012), Fernand Braudel (2009, 2013), Peter Burke (2011a, 2011b), François Dosse (2012), Jacques Le Goff (2013) e José D’Assunção Barros $(2011,2013)$.
} 
Assim como a História, a Geografia Histórica não precisa, ou melhor, não deve ser definida pelo passado, uma vez que ela também pode incorporar o presente ao seu horizonte temporal de análise. Afinal de contas, o presente também é histórico e caracterizado por diversas temporalidades que o atravessam e o constituem. Portanto, existe a possibilidade teórica de a Geografia Histórica se apropriar do presente.

Se a Geografia Histórica não deve ser definida como um campo, então qual é a nossa proposta? Compreendê-la como um método, uma forma de apreender processos e fenômenos, que pode ser empregado para qualquer campo da Geografia Social.

Em trabalho anterior (RODRIGUES, 2015), esforçamo-nos para definir a Geografia Histórica como um campo. Obviamente que agora estamos criticando nossa própria posição. No entanto, nem tudo precisa ser descartado. Naquela ocasião, sugerimos a ideia de que:

o campo da Geografia Histórica deve ser capaz de trabalhar com a relação indissociável entre tempo e espaço, temporalidade e espacialidade, onde a História, o Tempo e a Temporalidade não são meramente instrumentos auxiliares que permitem uma vaga contextualização ou moldura da análise geográfica, mas compõe, tal qual a espacialidade, o centro da análise (RODRIGUES, 2015, p. 251, grifos nossos).

Podemos ver o equívoco da formulação. O que está proposto não pode constituir um campo, mas sim um método. No entanto, há algo para se aproveitar. Se um campo não pode ser demarcado pela articulação densa entre tempo e espaço, é possível formular uma proposição metodológica a partir desses termos. A relação indissociável entre espacialidade e temporalidade implica, necessariamente, a articulação das categorias históricas no mesmo plano das categorias e conceitos da Geografia, sem hierarquização entre elas. Nessa perspectiva, o tempo histórico é compreendido como uma produção, uma fabricação social (KOSELLECK, 2012). Portanto, trata-se de um processo aberto, sempre inacabado. No entanto, como nos lembra Ruy Moreira (2019) $)^{5}$ o tempo e a história necessitam, obrigatoriamente, de uma espacialidade que permita a ação, a expressão do conteúdo social. Tal espacialidade, portanto, é igualmente produto social; logo, é produto histórico e condição para a própria história. No mesmo sentido, Carlos Walter Porto Gonçalves (2002, p. 310) afirma que:

a sociedade no seu devir histórico não é a-geográfica. A expressão, por certo, causa um certo estranhamento, embora seja natural dizer-se que o espaço que vivemos está impregnado de história. É como se fosse natural falar da historicidade do espaço geográfico e não de uma geograficidade da história. Poderíamos, à guisa de provocação epistemológica, afirmar que se a história se faz geografia é porque, de alguma forma, a geografia é uma necessidade histórica e, assim, uma condição de sua existência que, como tal, exerce uma coação que, aqui, deve ser tomada ao pé da letra, ou seja, como algo que co-age, que age com, é co-agente.

Essa proposição busca superar hierarquias e sobredeterminações entre espaço e tempo, chamando a atenção para o seu caráter imanente às relações sociais. Portanto, tomamos a espacialidade e a temporalidade como atributos constitutivos das sociedades, não exteriores, não hierárquicos e relacionais. Assim, o espaço social e o tempo histórico são produtos da ação social e, ao mesmo tempo, condições de existência e reprodução dessa própria ação.

${ }^{5}$ O belo título do livro de Ruy Moreira é a melhor síntese para compreender essa proposição: Espaço, corpo do tempo. 
Aqui é importante ressaltar as formulações de Antonio Carlos Robert de Moraes (2000, $2005,2014)$, nas quais explicita e propõe fundamentos metodológicos para a Geografia Humana. Nessas contribuições, não existe a defesa da Geografia Histórica como um campo, mas a incorporação explícita e clara da História nos fundamentos teóricos e metodológicos de constituição da própria Geografia, o que é fundamental. Moraes não está preocupado em demarcar uma campo para a Geografia Histórica, mas sim explicitar a historicidade imanente, indissociável e incontornável da Geografia Humana. É daí que extraímos parte significativa de nossa crítica à Geografia Histórica como campo e a situamos no plano do método. Assim, o que nos separa do autor é a distinção radical entre sociedade e espaço 6 .

De qualquer forma, a Geografia, nessa perspectiva, possui como objeto de análise a espacialidade das relações sociais. Tal espacialidade pode ser apreendida em qualquer período histórico. Uma vez que toda sociedade, em qualquer tempo, produz e institui uma espacialidade, ao mesmo tempo que é produzida e instituída por ela, é legítimo o interesse do geógrafo pela pesquisa em outros períodos históricos do passado, mas nada impede o mesmo tratamento metodológico para o chamado presente. Não há, portanto, justificativa teórica e empírica para limitar a Geografia Histórica ao passado. De acordo com Moraes (2000, p. 3),

Pode-se, portanto, dizer que qualquer período da história e em qualquer sociedade existe uma geografia (material e discursiva) que compõe a cultura de cada grupo social e de cada civilização. A variedade destas geografias é inerente à variedade de culturas existentes na história humana. Logo, há a necessidade de diferenciar e historicizar as culturas para bem contextualizar suas geografias.

O que significa tomar a Geografia Histórica como um método? Significa explicitar uma forma de se fazer Geografia, uma forma de apreender a espacialidade do social. Significa, portanto, explicitar uma maneira de se aproximar, construir e analisar um objeto, em que as categorias históricas estão no mesmo plano das categorias geográficas e são centrais para a análise. Assim, a História deixa de ser apenas uma contextualização ou uma bengala que apoia a análise geográfica e passa a constituir um dos alicerces da pesquisa. Em vez do famoso e enfadonho "breve histórico", das burocráticas contextualizações e recuos no tempo em que nada contribuem para o debate central, uma explicitação das categorias históricas e sua utilização para a análise.

Esta proposta de conceber a Geografia Histórica como um método fundamentado na articulação densa e não hierárquica entre as categorias e conceitos geográficos e históricos

\footnotetext{
6 "Nesse sentido, deve-se ter cautela ao definir a relação sociedade/espaço como objeto geográfico, pois tal enunciado sugere uma associação entre duas partes que se determinam reciprocamente, e que, portanto, entram com o mesmo peso na relação. E não se trata disso no caso, na medida em que o dinamismo que impulsiona o relacionamento de um grupo humano com um dado meio está totalmente localizado no âmbito do grupo, na verdade são os contatos entabulados entre seus membros que definem a forma de relacionamento de todos e de cada um com o espaço em que vivem. Assim, a relação sociedade/espaço é em si mesma entendida como uma relação social. A noção de espaço banal procura deixar bem evidente esse entendimento, ao avaliá-lo como um suporte que se qualifica pelo seu uso social e que se re-qualifica quando esse uso se altera. Aqui vai se trabalhar com a visão restrita que circunscreve apenas o que Milton Santos concebe como materialidade do espaço, a faceta que ele define como um 'sistema de objetos' (Santos, 1996), deixando o 'sistema de ações' fora da definição do espaço, como um domínio intrínseco do ser social. A nosso ver, as ações se objetivam no plano exclusivo da intencionalidade humana, sendo emanações da sociedade e dos sujeitos (individuais e coletivos) que a compõem. O espaço, nesse entendimento, é tomado como matéria que se qualifica pelo uso social a cada momento. Em suma, acata-se totalmente o seguinte juízo: 'o que faz de uma região da Terra um território de caça é o fato de uma tribo ali caçar’ (Marx, 1975)” (MORAES, 2014, p. 24).
} 
é tributária de uma perspectiva que não é nova na Geografia. Aqui nos remetemos às formulações realizadas, desde o século XIX e, principalmente, no século XX, no âmbito da Geografia, que enfatizam a necessidade do tratamento indissociável do tempo e do espaço. Tais esforços não são novos e nos legaram valiosas contribuições e reflexões que colocam a necessidade do tratamento teórico, conceitual e metodológico da dinâmica do espaço-tempo de forma indissociável. Assim, reivindicando ou não a Geografia Histórica, inúmeros geógrafos explicitaram esse fundamento teórico e metodológico e o desenvolveram dentro do escopo de suas obras, de seu tempo e seu lugar no mundo. Recentemente, Rogério Haesbaert (2021), no livro Território e descolonialidade: sobre o giro (multi)territorial/de(s) colonial na América Latina, traz um debate sobre a indissociabilidade espaço-tempo e recupera as contribuições de David Harvey, Nigel Thrift e Doreen Massey. No Brasil, para citar poucos exemplos, temos Milton Santos, em O espaço dividido e A natureza do espaço, e Ruy Moreira, em Espaço, corpo do tempo. Na Geografia Histórica brasileira, temos quase todas as obras de Maurício Abreu, Pedro Vasconcelos e Antonio Carlos Robert de Moraes. Antes de todos eles, no século XIX, não podemos nos esquecer de Élisée Reclus (1905), com sua obra-prima $O$ Homem e a Terra. Portanto, não estamos, obviamente, partindo do zero, mas, ao contrário, subindo nos ombros de gigantes.

Agora, voltando à questão do método, podemos desdobrar a questão em dois pontos: um diz respeito ao plano teórico e conceitual, e o outro, a procedimentos operacionais da pesquisa. Evidentemente que eles estão articulados, no entanto, para facilitar a apresentação, faremos uma separação arbitrária.

No primeiro, o geógrafo deve explicitar as categorias e conceitos históricos fundamentais para o trabalho de pesquisa ${ }^{7}$. No entanto, tal explicitação, ou seja, a apresentação do conteúdo, não deve ser burocrática e abstrata, mas sim articulada com o conjunto de fenômenos e processos que foram tomados como objetos de pesquisa ${ }^{8}$. De outro modo, a explicitação pode se tornar apenas um exercício de erudição, descolado dos conceitos e categorias da Geografia, o que iria reproduzir a dicotomia e dar uma falsa sensação de articulação.

O segundo ponto se refere mais diretamente aos procedimentos da pesquisa, particularmente ao processo de periodização $0^{9}$. A periodização ${ }^{10}$ pode ser definida como

7 É possível fazer uma grande lista de categorias e conceitos que podem e devem ser incorporados ao arsenal teórica da Geografia: tempo, temporalidade, historicidade, presente, passado, futuro, memória, aceleração, modernização, progresso, estrutura, conjuntura, evento, ritmo, ciclo, duração, permanência, experiência, entre outras. Sem dúvida, a Geografia já trabalha, há muito tempo, com tais categorias e conceitos, no entanto o tratamento teórico propriamente histórico pode ser aprofundado.

${ }^{8}$ Qual é a temporalidade de determinado processo ou fenômeno? De que forma diferentes temporalidades participam do processo de produção do espaço? De que forma diferentes temporalidades se articulam? Qual é o sentido da experiência concreta do tempo histórico para determinada classe ou grupo social? Qual é o tempo dominante? Quais são os tempos da resistência? Como a memória, o progresso e a modernização se constituem como elementos da análise histórica e são mobilizados politicamente? Como estrutura, conjuntura e eventos se articulam? Existe um tempo do mundo? Enfim, são inúmeras possibilidades.

9 Em relação à periodização, existem contribuições cruciais na própria Geografia brasileira, tais como as formulações de Milton Santos (1996), Miltons Santos e María Laura Silveira (2000), Pedro Vasconcelos (2002) e Maurício Abreu (2010).

10 "Especificado o lugar, há que se dar conta agora da periodização a ser utilizada no trabalho. Como todos sabemos, periodizações são segmentos de tempo que apresentam forte coalescência entre seus elementos constituintes ou, como queria Milton Santos, 'são conjuntos de relações e de proporções prevalentes ao longo de um certo pedaço do tempo'. Há, entretanto, alguns problemas com as periodizações. Em primeiro lugar, porque todas elas são arbitrárias, isto é, dependem daquilo que se quer analisar e da escala de observação utilizada. Em segundo lugar, porque raramente condizem com o tempo dos calendários, o que permite que se fale de um 'longo século XVI', como quis Braudel, ou de um 'curto século XX', como a ele se referiu Hobsbawm. Finalmente, porque elas tendem a priorizar temporalidades hegemônicas e a ação do Estado e agentes poderosos da sociedade, dando, por conseguinte, menor importância aos agentes subalternos e aos 'tempos lentos', isto é, às temporalidades não hegemônicas' (ABREU, 2010, p. 21). 
o exercício de recortar o tempo com o objetivo de identificar unidades específicas dotadas de certo grau de coerência e estabilidade, conferidas por determinados elementos que a constituem e são devidamente explicitados pelo pesquisador. Assim, a periodização é um exercício intelectual e arbitrário que produz um complexo temporal, uma unidade histórica. Periodizar significa estabelecer recortes, instituir limites, operar demarcações e rupturas no tempo: onde iniciar e parar o recorte? São os processos e fenômenos relativos à questão e ao objeto que permitem ao geógrafo operar tais ações. O trabalho será mais consistente quanto maior for a capacidade do pesquisador em estabelecer periodizações coerentes, o que significa dizer que o processo de periodização sempre deve estar acompanhado de uma justificativa clara e explícita. Nesse sentido, é crucial que os elementos constitutivos e os critérios de periodização, ou seja, aqueles que dão consistência e coerência interna ao recorte histórico, sejam explicitados e justificados. Refletindo sobre uma periodização para a história do território brasileiro, Santos e Silveira (2000, p. 23, grifo dos autores) ${ }^{11}$ afirmam que a "questão é escolher as variáveis-chave que, em cada pedaço de tempo, irão comandar o sistema de variáveis, esse sistema de eventos que denominamos período". E continuam: "períodos são pedaços de tempo definidos por características que interagem e asseguram o movimento do todo" (2000, p. 24). Os autores estão pensando na periodização sempre na tentativa de apreender a totalidade, o movimento global da sociedade. De forma mais modesta, ainda que sem desconsiderar a totalidade e, mais importante, estando sempre atento ao seu movimento, existem trabalhos e questões que podem usar critérios de periodização que não estejam diretamente preocupados com o movimento do todo, mas de certas partes, conjunturas ou eventos.

Ainda em relação à questão da periodização, não podemos deixar de mencionar a importante e robusta produção no campo da Geografia Histórica sobre tal questão, principalmente a partir da obra de Lawrence Estavile (1991). Partindo da questão da sincronia e diacronia, o autor elabora um quadro metodológico de periodização das pesquisas a partir dos cortes temporais, que podem ser, fundamentalmente, de três tipos: 1) Corte temporal transversal: é a definição de determinado período de tempo em que se prioriza a análise da sincronia, ou seja, da coexistência dos eventos e processos. Esse corte pode ser feito no passado ou pode ser um estudo do passado a partir dos vestígios encontrados no presente.

2) Corte sincrônico: refere-se ao recorte de diversos períodos históricos, tendo como objetivo principal identificar e analisar, de forma comparativa, as transformações e permanências da estrutura sócio-espacial. Nesse sentido, é possível, por meio de recortes sincrônicos específicos, analisar pontualmente a dinâmica de determinados processos.

3) Corte diacrônico: nesta perspectiva, a ênfase maior está na análise de um processo contínuo ao longo do tempo sem interrupções significativas (relativas, evidentemente, ao próprio processo ou fenômeno).

A escolha de cada tipo de periodização ou a utilização de mais de um corte dependerá, efetivamente, do tipo de pesquisa e das questões colocadas pelo pesquisador. A priori, nenhuma é pior ou melhor do que a outra, já que todas apresentam vantagens e desvantagens. Tais formulações, na Geografia Histórica, tornaram-se uma das pedras angulares da

\footnotetext{
${ }^{11}$ Nesta obra, tomando como critério de periodização o desenvolvimento e a disseminação desigual das técnicas que produzem e organizam o território usado, os autores sugerem a seguinte periodização: os meios "naturais", o meio técnico e o meio técnico-científico-informacional. Cada um desses meios constitui um período histórico específico do processo de formação do território brasileiro (p. 27).
} 
orientação metodológica, como sugerem, por exemplo, Pedro Vasconcelos (1999) e Marcelo Werner da Silva (2012).

Em função do espaço restrito deste texto, estamos caminhando para o fim. No entanto, antes de terminar, apresentaremos, ainda que de forma superficial, algumas possibilidades de uso de categorias e conceitos históricos que podem se articular com a Geografia e, dessa forma, produzir uma análise mais potente da espacialidade do social.

O primeiro exemplo é de Fernand Braudel, autor-chave para a obra de Pedro Vasconcelos. Braudel possui duas formulações que poderiam ser explicitadas e incorporadas pelos geógrafos de todos os campos específicos da Geografia Social. São elas: 1) O tempo do mundo; 2) Os tempos da história: os eventos, as conjunturas e a longa duração.

O tempo do mundo é uma expressão que aparece, rapidamente, no artigo História e Ciências Sociais: a longa duração, publicado originalmente em 1958. Neste trabalho, Braudel não desenvolve a ideia, e a expressão é utilizada para demarcar certa originalidade da História em relação às Ciências Sociais. O trecho em que a expressão aparece é o seguinte:

Cada realidade social secreta seu tempo ou suas escalas de tempo, como vulgares conchas. Mas o que nós, historiadores, ganhamos com isso? A imensa arquitetura dessa cidade ideal permanece imóvel. A história está ausente dela. O tempo do mundo, o tempo histórico aí se encontra, mas como vento em Éolo, encerrado numa pele de bode. Não é à história que os sociólogos, final e inconscientemente, querem mal, mas ao tempo da história (BRAUDEL, 2013, p. 75, grifos nossos).

A expressão torna-se ideia no prefácio do terceiro volume da grande obra Civilização material, economia e capitalismo: séculos XV-XVIII, cujo subtítulo é exatamente O tempo do mundo. Curiosamente, o autor parece esquecer que a utilizou no artigo de 1958 e atribui sua criação ao historiador Wolfram Eberhard, em um livro de 1970 chamado Conquerors and Rules. Social Forces in Medieval China. No prefácio da obra, diz Braudel (2009, p. 7, grifos do autor): "Retomando a feliz expressão de Wolfram Eberhard, intitulei-o O tempo do mundo, seguramente um belo título, se bem que promete mais do que poderei dar".

No prefácio, Braudel transforma a expressão em ideia. Para o historiador francês, é possível identificar, qualificar e experimentar um

tempo vivido nas dimensões do mundo, o tempo do mundo, que no entanto, não é não deve ser, a totalidade da história dos homens. Esse tempo excepcional rege, conforme os lugares e as épocas, certos espaços e certas realidades. Mas outras realidades, outros espaços lhe escapam e lhe são estranhos [...].

O tempo do mundo referir-se-ia portanto a uma espécie de superestrutura da história global: seria uma espécie de consumação, como que criada e suscitada pelas forças que exercem abaixo dela, embora seu peso repercuta, por sua vez, na base. Conforme os lugares e as épocas, essa dupla ação de baixo para cima e de cima para baixo foi mais ou menos importante. Mas nas regiões avançadas, econômica e socialmente falando, o tempo do mundo não urdiu tudo (BRAUDEL, 2009, p. 8, grifos do autor).

O tempo do mundo nos permite, em primeiro lugar, mapear as diferentes temporalidades que são coexistentes. Em outras palavras, a ideia de tempo do mundo nos permite apreender a espacialidade dos diferentes tempos sociais que coexistem no mesmo plano cronológico. Essa cartografia permite ressaltar as relações que se estabelecem ou não entre os diferentes espaços, suas qualidades, propriedades e intensidades. Uma vez que 
o tempo do mundo não é a soma das histórias dos homens, mas um tipo específico de temporalidade que é vivenciada nas dimensões do mundo, ela ganha qualidades analíticas e políticas fundamentais: o tempo de qual território se constitui como tempo do mundo? Como? Por quê? Quais são seus elementos estruturais?

A ideia de tempo do mundo, sem dúvida, oferece-nos a possibilidade de uma apreensão mais rigorosa, qualificada e profunda dos sentidos da história e da espacialidade, pois nos conduz à busca dos elementos estruturais que dão sentido aos processos e, dessa forma, permitem uma análise (sempre crítica) radical que apreende os fundamentos da organização social (ARANTES, 2014). Essa perspectiva contribui para aqueles geógrafos que trabalham na perspectiva da totalidade, tão cara, por exemplo, a Milton Santos (1996) e Ruy Moreira (2012), que buscam, cada um a seu modo, explicitar os fundamentos da espacialidade do social.

Além do tempo do mundo, a ideia dos tempos históricos presentes na obra de Braudel é riquíssima para a Geografia, como demonstra o trabalho de Pedro Vasconcelos (2002), que se apropriou e explicitou tal formulação em seu trabalho sobre Salvador.

Braudel identifica três tempos históricos que constituem a vida social:

1) Os eventos - acontecimentos breves, instantâneos, matéria dos cronistas e jornalistas, como um encontro, um incêndio, um discurso, uma tempestade. Os eventos são os acontecimentos sucessivos da vida individual e coletiva, em que as experiências concretas são vivenciadas. No entanto, ainda que parte de nossa história seja vivenciada neste tempo, ele possui uma limitada capacidade analítica. Braudel (2013, p. 23) compara os eventos a vagalumes, cujas "luzes pálidas reluziam, se extinguiam, brilhavam de novo, sem romper a noite com verdadeiras claridades. Assim são os acontecimentos: para além de seu clarão, a obscuridade permanece vitoriosa”. Assim, o acontecimento, sozinho, não é capaz de explicar a si mesmo e não possui os elementos necessários que nos permitam apreender a história em sua complexidade; não possibilitam a identificação e a análise dos processos e estruturas mais profundos sobre as quais eles estão assentados e que são uma condição de existência do próprio evento.

2) As conjunturas - em vez da instantaneidade do evento, as conjunturas são períodos maiores de tempo que possuem grande elasticidade, podendo durar de 4 ou 5 anos até 50 ou 100 anos (BRAUDEL, 2009, 2013). São períodos caracterizados por ciclos e movimentos periódicos. Assim como os eventos ocorrem simultaneamente uns aos outros, aos milhões, devemos falar em conjunturas que coexistem, articulam-se, atravessam-se. Esse tempo histórico é aquele que assenta os eventos e, em uma perspectiva analítica, permite ultrapassá-los, enquadrá-los e, assim, produzir uma análise mais substancial e robusta. A conjuntura, nessa perspectiva, apresenta-se como um elemento analítico fundamental, pois é, ao mesmo tempo, o assento histórico dos eventos e um movimento da própria estrutura: quanto maior a conjuntura, mais próxima da estrutura ela está e maior é a explicitação dos elementos estruturais e suas características.

3) A longa duração - é o tempo das grandes estruturas sociais que parecem imóveis, quase que fora do tempo e da própria história. Sua duração é de séculos: levam séculos para serem produzidas e outros séculos para serem destruídas. Sobre tais estruturas, Braudel (2013, p. 49, grifo do autor) afirma que:

Boa ou má, ela domina os problemas da longa duração. Por estrutura, os observadores do social entendem uma organização, uma coerência, relações bastante fixas entre 
realidades e massas sociais. Para nós, historiadores, uma estrutura é, sem dúvida, articulação, arquitetura, porém, mais ainda, uma realidade que o tempo utiliza mal e veicula mui longamente. Certas estruturas, por viverem muito tempo, tornam-se elementos estáveis de uma infinidade de gerações: atravancam a história, incomodamna, portanto, comandam-lhe o escoamento. Outras estão mais prontas a se esfarelar. Mas todas são, ao mesmo tempo, sustentáculos e obstáculos.

Braudel, sem dúvida, indica a longa duração como tempo histórico central em suas reflexões. Para ele, é neste tempo que se colocam as questões mais pertinentes de serem investigadas pela História. No entanto, isso não significa desprezar os eventos e, muito menos, as conjunturas. O que explica a centralidade da longa duração é sua preocupação com a síntese global da sociedade, portanto com a totalidade. A síntese necessita da articulação entre os três tempos históricos, mas a expressão final dessa síntese só pode ser efetivamente explicitada se for localizada na longa duração. Daí podemos reter duas lições importantes para a Geografia Histórica como um método:

1) A ideia da arquitetura dos tempos históricos (BARROS, 2013). Os diferentes tempos históricos se articulam, entrelaçam-se, perpassam uns aos outros. A tarefa fundamental é identificar o tempo histórico de cada um dos processos e fenômenos que estão delimitados em uma pesquisa e a função que desempenham dentro da totalidade ${ }^{12}$.

Quer se situe em 1558 ou no ano da graça de 1958, trata-se, para quem quer compreender o mundo, de definir uma hierarquia de forças, correntes, de movimentos particulares, depois, apreender de novo uma constelação de conjunto. A cada instante dessa pesquisa, será preciso distinguir entre movimentos longos e impulsos breves, estes, tomados desde suas fontes imediatas, aqueles, no impulso de um tempo longínquo. O mundo de 1558, tão enfadonho no momento francês, não nasceu ao umbral desse ano sem encanto. E tampouco, sempre no momento francês, nosso difícil ano de 1958. Cada "atualidade" reúne movimentos de origem, de ritmo diferentes. O tempo de hoje data, ao mesmo tempo, de ontem, de anteontem, de outrora (BRAUDEL, 2013, p. 54).

2) A ideia de espessura do tempo histórico. Tal ideia busca apreender a densidade, a profundidade com que cada elemento, processo ou fenômeno atua na constituição e reprodução social, mais do que sua duração cronológica em si. A espessura histórica diz respeito ao grau de intensidade com que algo participa ativamente do mundo aqui e agora. Quando chamamos a atenção para esse aspecto, desejamos ressaltar a atualidade de cada elemento, ou seja, a forma como ele é atual no sentido de estar presente, vivo e, portanto, atuante. $\mathrm{O}$ atual não é necessariamente novo, e esse é um mal-entendido muito comum. O atual é o que atua, age, imprime movimento, constrange, dinamiza. O que é atual pode ter surgido há séculos. Basta pensar, por exemplo, no racismo, no capitalismo ou no machismo: estruturas sociais seculares que constituem a sociedade hoje e participam ativamente de sua estruturação e reprodução; portanto, atuais e de larga espessura histórica.

A explicitação e a articulação entre o tempo do mundo e os tempos históricos abrem ricas possibilidades para a Geografia como um todo e contribuem para reforçar nossa proposição em relação à Geografia Histórica. Não há dúvidas da funcionalidade da incorporação de tais conceitos históricos à Geografia, principalmente quando podemos articulá-los com formulações que partem de elementos comuns, como as obras de Milton Santos, Ruy

\footnotetext{
${ }^{12}$ Essa lição está formulada, com outras palavras, em A natureza do espaço, de Milton Santos.
} 
Moreira ou David Harvey $(1996,2015)$. Em outras palavras, é possível a explicitação teórica da perspectiva histórica articulada com um patrimônio teórico que já existe na Geografia.

O segundo e último exemplo é de Reinhart Koselleck, historiador alemão e autor de uma vasta obra nos campos da historiografia e história dos conceitos. Koselleck possui duas categorias que devem ser trabalhadas de forma articuladas e com grande potencial para enriquecer a Geografia Histórica na perspectiva que apresentamos ao longo deste trabalho: espaço de experiência e horizonte de expectativas (KOSELLECK, 2012, p. 305-328).

Essas categorias exprimem a condição universal de existência da própria história, uma vez que esta não existe sem uma experiência prévia e que não seja motivada por alguma expectativa. Além disso, experiência e expectativa remetem, necessariamente, uma à outra, é um par indissociável, afinal não há experiência sem expectativa e não há expectativa sem experiência. Ainda, experiência e expectativa são categorias históricas que equivalem, respectivamente, a espaço e tempo.

O espaço de experiência indica um lugar concreto de vivência do tempo histórico. Segundo o autor,

A experiência é o passado atual, aquele no qual acontecimentos foram incorporados e podem ser lembrados. Na experiência se fundem tanto a elaboração racional quanto as formas inconscientes de comportamento, que não estão mais, ou que não precisam mais estar presentes no conhecimento. Além disso, na experiência de cada um, transmitida por gerações e instituições, sempre será contida e é conservada uma experiência alheia. Nesse sentido, também a história é desde sempre concebida como conhecimento de experiências alheias (KOSELLECK, 2012, p. 309-310).

O horizonte de expectativas, maior ou menor, mais próximo ou distante, refere-se ao futuro: a esperança, o desejo, o medo, a salvação, a danação etc. Sobre a expectativa,

também ela é ligada à pessoa e ao interpessoal, também a expectativa se realiza no hoje, é futuro e presente, voltado para o ainda-não, para o não-experimentado, para o que apenas pode ser previsto. Esperança e medo, desejo e vontade, a inquietude, mas também a análise racional, a visão receptiva ou a curiosidade fazem parte da expectativa e a constituem (KOSELLECK, 2012, p. 310).

Ainda que não seja possível deduzir completamente uma expectativa de determinadas experiências, elas se relacionam e constituem as condições de existência do tempo histórico. Para Koselleck, toda ação se realiza a partir da experiência adquirida e vivenciada e das expectativas dos sujeitos. A ação é produto dessas duas temporalidades, nas quais se entrelaçam passado, presente e futuro. $O$ passado é constituído por toda a experiência individual e coletiva, e o futuro é o horizonte de expectativa individual e coletiva. Assim, as duas temporalidades expressas pela experiência e pela expectativa se relacionam reciprocamente de diversas formas, o que abre um leque gigantesco de possibilidades analíticas, permitindo a incorporação substancial e efetiva da historicidade ao trabalho do geógrafo.

As categorias de Koselleck podem ser utilizadas em qualquer escala, do lugar ao global, e podem ser úteis para historicizar os processos de territorialização e produção do espaço em qualquer campo da Geografia Social. São categorias que nos permitem pensar na totalidade, porém também podem ser utilizadas em trabalhos e pesquisas que não compartilham dessa perspectiva. No entanto, não temos dúvidas de que podem ser ferramentas importantes para a análise da espacialidade social. 
O objetivo central deste texto foi elaborar uma crítica inicial à ideia de se tomar a Geografia Histórica como um campo da disciplina, como a Geografia Urbana, a Geografia Agrária etc. Para sustentar essa crítica, argumentamos que um campo não pode ser definido apenas por um horizonte temporal, nesse caso, o passado, mas necessita da delimitação de conjunto de processos e fenômenos empíricos com forte identidade entre si. Além disso, afirmamos que nem mesmo a História se define pelo estudo do passado, mas sim pelo estudo do homem no tempo, ou seja, define-se como disciplina quando se propõe a analisar a sociedade pela perspectiva temporal, o que significa produzir conceitos e categorias que explicitem a temporalidade e a historicidade dos processos. Portanto, se nem a História se define pelo estudo do passado, por que a Geografia Histórica deveria ser definida dessa forma?

Se a História se define por essa perspectiva de apreender a ação social por meio de uma de suas dimensões, a Geografia Histórica deveria ter como uma de suas preocupações centrais a explicitação de conceitos e categorias históricas no mesmo plano das categorias e conceitos geográficos para a elaboração de suas análises. O adjetivo "histórica" impõe essa necessidade e esse desafio ao geógrafo. Historicizar é mais do que indicar uma data, um corte cronológico ou fazer uma contextualização. Historicizar é explicitar a dimensão temporal e histórica de um processo ou fenômeno para além de constatações banais. É necessário, portanto, dominar e explicitar os conceitos e categorias e de que forma eles estão relacionados com os processos de produção do espaço.

A explicitação e a articulação de categorias e conceitos históricos e geográficos em um mesmo plano analítico nos permitem tecer inúmeros fios e produzir uma teia, um feixe constituído por diferentes temporalidades, ritmos, períodos, historicidades, escalas, territorialidades e espacialidades. Os feixes que constituem esse complexo tecido possuem espessuras e comprimentos diferentes, dando origem ao que se pode denominar complexo espaço-tempo. Assim, é provável que, para compreender e analisar objeto qualquer, é preciso lidar, ao mesmo tempo, com processos e elementos constitutivos que remetem à longa duração e a estruturas socioespaciais, com outros que remetem ao horizonte espaçotemporal da conjuntura e, por fim, com aqueles que remetem aos eventos. Historicidades e temporalidades distintas que possuem escalas geográficas (tanto de abrangência quanto de análise) e espacialidades distintas. Portanto, cada elemento ou processo que constitui, influencia ou condiciona nosso objeto deve explicitar sua historicidade, temporalidade, espacialidade e suas escalas de análise. Esse procedimento deixa clara a necessidade de se levar em conta o caráter multiescalar da pesquisa e da historicidade dos processos, que se articulam no tempo e no espaço.

Quando a Geografia Histórica, na sua longa tradição, incorpora de forma explícita a História, ela não constitui um campo, mas uma forma de olhar o mundo, uma forma de pensar e fazer Geografia, uma forma de construir e interrogar um objeto geográfico. É uma possibilidade de produção de conhecimento, e não um campo novo. A Geografia Histórica, nesse sentido, é um enfoque, uma perspectiva de olhar o mundo e apreendê-lo de forma sistemática. Como método, ela:

1) Coloca no mesmo plano teórico as categorias geográficas e históricas.

2) Busca produzir análises por meio da articulação indissociável entre espaço e tempo.

3) Pode ser utilizada para o estudo de qualquer processo ou fenômeno da Geografia Social. 


\section{Bibliografia}

ABREU, M. A. Sobre a memória das cidades. Território, Rio de Janeiro, v. 3, n. 4, p. 5-26, 1998.

ABREU, M. A. Construindo uma Geografia do passado: Rio de Janeiro, cidade portuária, século XVII. Geousp, São Paulo, v. 4, n. 1, p. 13-25, 2000.

ABREU, M. A. Geografia Histórica do Rio de Janeiro (1502-1700). Rio de Janeiro: Andrea Jakobson, 2010. ARANTES, P. O novo tempo do mundo. São Paulo: Boitempo, 2014.

BAKER, A. Geography and history: bridging the divide. Cambridge: Cambridge University Press, 2003. BARROS, J. D. A. Teoria da história. Petrópolis: Vozes, 2011, v. I: Princípios e conceitos fundamentais.

BARROS, J. D. A. O tempo dos historiadores. Petrópolis: Vozes, 2013.

BLOCH, M. Apologia da história ou o ofício do historiador. Rio de Janeiro: Jorge Zahar, 2009.

BRAUDEL, F. Civilização material, economia e capitalismo: séculos XV-XVIII . São Paulo: Martins Fontes, 2009, v. 3: O tempo do mundo.

BRAUDEL, F. Escritos sobre a história. São Paulo: Perspectiva, 2013.

BURKE, P. A escrita da história: novas perspectivas. São Paulo: Unesp, 2011 a.

BURKE, P. História e teoria social. São Paulo: Unesp, 2011b.

CARNEIRO, P. A. S. Origens e evolução da geografia histórica. Revista Eletrônica da Associação dos Geógrafos Brasileiros, Três Lagoas, v. 13, n. 23, p. 42-65, 2016.

CORTEZ, C. Geografia histórica. Cidade do México: Instituto Mora, 1991.

DOSSE, F. A. História. São Paulo: Unesp, 2012.

ESTAVILE, L. Organizing time in historical geography. In: GREEN, D. B. (Org.). Historical geography: a methodological portrayal. Savage, MD: Rowman \& Littlefield, 1991.

GOFF, J. L. História e memória. São Paulo: Unicamp, 2013.

GONÇALVES, C. W. P. Da geografia às geo-grafias: um mundo em busca de novas territorialidades. In: SADER, E.; CECEÑA, A. E. (Ed.). La guerra infinita: hegemonía y terror mundial. Buenos Aires: CLACSO, 2002.

GREGORY, D. The discourse of the past: phenomenology, structuralism and historical geography. Journal of Historical Geography, London, v. 4, n. 2, p. 161-173, 1978.

GREGORY, D. Action and structure in historical geography. In: BAKER, A. R. H.; BILINGE, M. (Org). Period and place: research methods in historical geography. Cambridge: Cambridge University Press, 1982.

HAESBAERT, R. Território e descolonialidade: sobre o giro (multi)territorial/de(s)colonial na América Latina. Ciudad Autónoma de Buenos Aires: CLACSO; Niterói: Programa de Pós-graduação em Geografía, 2021.

HARVEY, D. A condição pós-moderna. São Paulo: Loyola, 1996.

HARVEY, D. Paris, capital da modernidade. São Paulo, Boitempo, 2015.

KOSELLECK, R. Estratos do tempo: estudos sobre a história. Rio de Janeiro: Editora Puc Rio, 2006.

KOSELLECK, R. Futuro passado: contribuição à semântica dos tempos históricos. Rio de Janeiro: Editora Puc-Rio, 2012.

LOWENTHAL, D. Como conhecemos o passado. Revista do Programa de estudos pós-graduados em História e Departamento de História, São Paulo, n. 17, p. 63-201, 1998. Projeto História - trabalhos de memória.

MONTENEGRO, A. T. História, metodologia, memória. São Paulo: Contexto, 2010.

MORAES, A. C. R. Geografia, história e história da geografia. Terra Brasilis, Niterói, v. 2, 2000.

MORAES, A. C. R. Geografia, interdisciplinaridade e metodologia. GEOUSP (Online), São Paulo, v. 18, n. 1, pp. 9- 39, 2014.

MORAES, A. C. R. Território e história no Brasil. São Paulo: Annablume, 2005.

MOREIRA, R. A formação espacial brasileira: contribuição crítica aos fundamentos espaciais da geografia do Brasil. Rio de Janeiro: Consequência, 2012.

MOREIRA, R. Espaço, corpo do tempo. Rio de Janeiro: Consequência. 2019.

NOGUEIRA, C. E. A geografia histórica como ferramenta de análise nos estudos de história do pensamento geográfico. Terra Brasilis (Nova Série), Niterói, v. 12, 2019.

NORTON, W. Historical analysis in geography. London: Longman, 1984.

NOVAIS, F. Aproximações: estudos de História e Historiografia. São Paulo: Cosac Naify, 2005. 
RECLUS, E. El hombre y la tierra. Barcelona: Publicaciones de La Escuela Moderna, 1905, tomo 1.

RODRIGUES, G. B. Geografia histórica e ativismos sociais. Geotextos, Salvador, v. 11, n. 1, p. 241-268, 2015.

SANTOS, M. A natureza do espaço. São Paulo: Hucitec, 1996.

SANTOS, M. O espaço dividido. São Paulo: Edusp, 2008.

SANTOS, M.; SILVEIRA, M. L. Brasil: território e sociedade no início do século XXI. São Paulo: Record, 2000.

SAUER, C. Introducción a la geografía histórica. Polis, Chile, v. 3, n. 8, 2004.

SCOTT, A.; STORPER, M. A natureza das cidades: a abrangência e os limites da teoria urbana. Geografares, Vitória, n. 27, p. 5-29, 2018.

SILVA, M. W. A geografia e o estudo do passado: conceitos, periodizações e articulações espaço-temporais. Terra Brasilis (Nova Série), Niterói, v. 1, 2012.

VASCONCELOS, P. A. Os agentes modeladores das cidades brasileiras do período colonial. In: CASTRO, I.; GOMES, P.; CORREA, R. (Org.). Explorações geográficas. Rio de Janeiro: Bertrand Brasil, 1997.

VASCONCELOS, P. A. Questões metodológicas na geografia urbana histórica. In: VASCONCELOS, P. A.; MELLO e SILVA, S. B. (Org.). Novos estudos de Geografia Urbana brasileira. Salvador: Editora da Universidade Federal da Bahia, 1999.

VASCONCELOS, P. A. Salvador: transformações e permanências (1549-1999). Ilhéus: Editus, 2002.

VASCONCELOS, P. A. Questões metodológicas na geografia urbana histórica. Geotextos, Salvador, v. 5, p. 147-157, 2009.

VASCONCELOS, P. A. Geografia Histórica: campo disciplinar e questões de pesquisa. In: ENCONTRO NACIONAL DE HISTÓRIA DO PENSAMENTO GEOGRÁFICO, 3., ENCONTRO NACIONAL DE GEOGRAFIA HISTÓRICA, 1. Rio de Janeiro, 2012. Palestra.

VASCONCELOS, P. A. O universo conceitual de Milton Santos. Curitiba: CRV, 2020.

SOBRE O AUTOR

Glauco Bruce Rodrigues. Professor do Departamento de Geografia e do Programa de Pós-Graduação em Geografia da Universidade Federal Fluminense - Campos dos Goytacazes (UFF/Campos).Coordenador do Núcleo de Estudos sobre o Território e Conflitos Sociais. 